\title{
Synergistic Effect of Barium Chloride on Corrosion Inhibition of Copper by Aqueous Extract of Lupine Seeds in Nitric Acid
}

\author{
Abd El-Aziz S. Fouda ${ }^{1,}$, Safaa El-din H. Etaiw ${ }^{2}$, Dina M. Abd El-Aziz ${ }^{2}$, and Osama A. Elbaz ${ }^{1}$ \\ ${ }^{1}$ Chemistry Department, Faculty of Science, Mansoura University, Mansoura-35516, Egypt \\ ${ }^{2}$ Department of Chemistry, Faculty of Science, Tanta University, Tanta, Egypt \\ *E-mail: asfouda@hotmail.com
}

doi: $10.0964 / 2017.07 .08$

Received: 7 December 2016/Accepted: 23 April 2017 / Published: 12 June 2017

Synergistic effect of $\mathrm{BaCl}_{2}$ on the corrosion inhibition efficiency of aqueous Lupine seed extract, on $(\mathrm{Cu})$ in $2 \mathrm{M} \mathrm{HNO}_{3}$ acid solution has been investigated using weight loss measurements, electrochemical impedance spectroscopy (EIS), electrochemical frequency modulation (EFM) and potentiodynamic polarization (PP) studies. The results show that inhibition efficiencies on $\mathrm{Cu}$ increase with increase in concentration of the extract and enhancement in inhibition efficiency was observed on addition of barium chloride due to synergism. The adsorptions, of extract and extract $+\mathrm{BaCl}_{2}$ on the surfaces of the corroding metal obey Langmuir isotherms. Polarization studies revealed that lupine extract acts as a mixed type inhibitor. Thermodynamic parameters were calculated using the adsorption isotherms. A probable synergistic mechanism is proposed. The film coated on $\mathrm{Cu}$ specimens was analyzed by using Fourier transform infrared spectroscopy (FT-IR). The surface shape was studied by using atomic force microscopy (AFM) analysis.

Keywords: Corrosion inhibition, Lupine seed extract, $\mathrm{HNO}_{3}, \mathrm{Cu}, \mathrm{BaCl}_{2}$, PP, EIS, EFM, AFM, FT-IR

\section{$\underline{\text { FULL TEXT }}$}

(C) 2017 The Authors. Published by ESG (www.electrochemsci.org). This article is an open access article distributed under the terms and conditions of the Creative Commons Attribution license (http://creativecommons.org/licenses/by/4.0/). 